\title{
Adriano Zambon*
}

\section{Property: A conceptual analysis}

This paper aims to explicate the concept of property, regarded as the minimal sense of the word "property", in ordinary as well as legal language. The main claim is that the concept of property consists in a set of one or more deontic modalities that regulate the relations between persons in connection with one or more goods. The concept of property is then distinguished from differing conceptions of property, and its relations with other legal concepts are analysed. Then, some observations on the criteria for applying the concept and on the transferability of property are presented. Finally, the utility of the knowledge of the concept of property is discussed.

Keywords: concept, conception, conceptual analysis, ownership, property, property rights, transfer

\section{INTRODUCTION}

My aim is to propose a definition of the word "property" that is able to express the minimal sense this word has when used in legal and ordinary language. ${ }^{1}$ After focusing on the problem of the definition of the term, I then distinguish two of its common uses. The attempt to find an explanation for these uses will lead me to identify the concept of property. The relations between the concept I identify and other proximal concepts (i.e. ownership, property rights, and contract rights) are then briefly analysed. I then discuss the criteria for applying the concept of property and its connection with the possibility to transfer property. Finally, I discuss some aspects of the utility provided by the newly detailed concept of property.

\section{THE DEFINITION OF "PROPERTY”}

The concept of property is notoriously hard to characterize. To identify the different problems, it is useful to recall a classification proposed by Herbert L. A. Hart. ${ }^{2}$ Hart identifies three problems regarding property (as well as punishment): the problem of its definition, the problem of its justification, and the problem of its distribution. The first problem is logically antecedent to the other

* adriano.zambon@unimi.it | Cesare Beccaria Department of Legal Studies, University of Milan.

1 The analysis here proposed, however, does not focus on the term "property" as used by metaphysicians (on this clarification, see Snare 1972: 200).

2 Hart 1968: 4. 
two: only after knowing what "property" means, it is possible to apply normative theories that allow one to solve the problems of its justification and distribution.

To define "property" means to express the concept of property. I regard the concept of property as the sense of the term "property", and I regard the sense of the term "property" as a set of attributes something must have to be designated by the word "property" (i.e. in order to be regarded as a reference of that word). 3 The concept of property may also be distinguished from the conceptions of property: a conception of property is a declension of the concept of property; two conceptions of property differ from each other because they are different declensions of the same concept, but they are similar in that they both share the same basic idea of property (which is the concept of property) as a starting point. This means that the concept of property is, more precisely, the minimal sense of the term "property", in that it is presupposed by any conception of property proposed by legal theorists or employed in legal systems. 4 This does not mean that there is no difference between uses of the term "property" found in differing contexts. Rather, differences between such uses exist because in different contexts one may find different conceptions of property; but the concept, i.e. the minimal sense of "property", is presupposed by all these conceptions and is always the same. 5

It should be noted that this view is contested by Hart himself. ${ }^{6}$ Hart claims that it is impossible to provide direct definitions of such words as "right", because there is no counterpart that can correspond perfectly to them. These words, then, should not be abstracted from the sentences in which they occur. Instead, legal philosophers should study such sentences in their entirety.

3 The notions of sense and reference come from Frege (1952), although their use here is not entirely Fregean. Such a use, however, excludes (at least prima facie) that a concept is a mental representation. See Claeys 2018, for a conceptual analysis of property based on the different idea that "[a] concept is a mental representation on which people rely as they perceive or transact with things associated with some field of human activity" (Claeys 2018: 230). And, for a more extensive treatment of the subject, see Munzer 2013: 301-303.

4 For a famous application of the distinction between concept and conceptions, see Rawls 1971: 5-11.

5 So, it is true that "[i]t would [...] be foolish to attempt a universal definition of the word 'property' such that it would enable conclusions to be read off from any constitutional or statutory provision which employed the term. How could one possibly assume, in advance of contextual enquiry, that all and only that which is 'property' for the purpose of constitutional provisions is also 'property' for the purposes of divorce jurisdictions, formality rules, and revenue law?" (Harris 1996: 12). Such a definition does not exist because it is impossible to equate all of the conceptions of property (which may be found, for example, in the constitutional or statutory provisions referred to by Harris) with each other. The general definition of the word "property" that can be attempted is only a description of the concept of property; it does not make the differences between the conceptions of property disappear, but it brings out a common element in all these conceptions.

6 See Hart 1954. 
A similar view seems to be employed by Alf Ross in his analysis of the term "ownership".7 He claims that this word, just like the word "right", is a tool in a technique of presentation, which means that it

is solely a means by which it is possible - more or less accurately - to visualise the content of a set of legal rules, namely, those that connect a certain disjunctive plurality of conditioning facts with a certain cumulative plurality of legal consequences. ${ }^{8}$

So, the word "ownership" constitutes a synthetic way to represent the legal rules that connect certain facts with certain legal consequences. This is why, according to Ross, the word "ownership" "does not designate any phenomenon of any kind that has inserted itself between the conditioning facts and the conditioned consequences". ${ }^{9}$ And this is why Ross writes that this term "inserted between the conditioning facts and the conditioned consequences is in reality a meaningless word, a word without any semantic reference whatever, serving solely as a tool of presentation". 10 The consequences of this idea are that a direct definition of "ownership" is not possible and that a concept of ownership regarded as a set of attributes specifiable through such a definition does not exist. It therefore seems reasonable to say that the concept of ownership is regarded by Ross as nothing but the term "ownership".

The contrast between the two views described here is apparent, but it is not my intention to provide reasons why one of them should always be preferred over the other. Instead, I will try to deal with the problem of the definition of property by following the first view, and I hope to show that this view is fruitful when applied to this problem.

\section{TWO USES OF “PROPERTY”}

The search for the attributes that compose the concept of property can start with a description of the common uses of the word. More precisely, by looking closely at what this term is used to designate (i.e. its references), it is possible to clarify its sense. First, the term "property" can be used to designate a good, which can be a material or immaterial thing. ${ }^{11}$ This happens, for example, in such sentences as "This land is private property", "This algorithm is intellectual property", "The entrance to this property is up a driveway", and so on. Second,

7 See Ross 1957 and Ross 1958: 170-175.

8 Ross 1958: 174.

9 Ross 1958: 174.

10 Ross 1957: 820. It is disputable that Ross's first idea ("ownership" is a tool in a technique of presentation) may be used to support his second idea ("ownership" does not have a meaning). On this point, see Sartor 2009: 37-42 and Brożek 2015: 15-19.

11 It is important to specify that here I use the term "immaterial" as a synonym of "not consisting of matter" (and not as a synonym of "of no importance"). 
the term "property" can be used to designate something that is not a good, but that has a good as its object. It is possible to formulate such sentences as "This book is the object of my property", "These assets are objects of public property", and "This contract concerns the property of confidential information". In these sentences the material or immaterial things designated by the names "book", "assets", and "information" are not designated by the term "property", but they seem to be the object of something that is designated by the term "property".

It seems that a person must know how to use the term "property" in the second way described, if he or she wants to use this term to designate a good. For, if we could not use "property" in the second way described, there would be no reason for us to employ this term to designate things that we can already designate without using "property". For example, we could simply employ the term "book" to designate a book. The reason why we use the term "property" as well, and not only the term "book", to designate that book, is that "property" carries a sense that is not the same sense of "book". This sense must be that the book is the object of that something that is designated by the term "property" in its second use and that is not the book. So, only if we know (more or less explicitly) that goods are objects of something that is called "property" and we know what that something is, can we use "property" to designate those goods.

It is important at this point to notice that the term "ownership" has a use that is similar to the second use of the term "property". As Anthony M. Honoré writes, "[t]here is, clearly, a close connexion between the idea of ownership and the idea of things owned, as is shown by the use of words such as 'property' to designate both". 12 The word "property", then, can be used to designate the same something designated by the word "ownership" and the things that are the object of that something that the word "ownership" designates: this means that the two terms may have the same sense.

\subsection{A negative thesis}

As mentioned, knowledge of the second use of the word "property" is a necessary condition of its first use. It is thereby essential to understand what the sense of "property" is when this term is used in the second way described above. We already know that in this second use, "property" does not designate a good and that it designates something that has a good as its object. What could this something be?

First, it cannot be a material thing. This negative thesis may strike us as obvious, ${ }^{13}$ but I think that it is interesting and worthwhile to (at least briefly)

12 Honoré 1961: 128.

13 As Morris R. Cohen writes, "[a]nyone who frees himself from the crudest materialism readily recognizes that as a legal term property denotes not material things" (M. R. Cohen 1927: 11). 
clarify the reasons behind its acceptance. Jeremy Bentham provides a clear explanation in the following passage of The Theory of Legislation:

There is no image, no painting, no visible trait, which can express the relation that constitutes property. It is not material, it is metaphysical; it is a mere conception of the mind. To have a thing in our hands, to keep it, to make it, to sell it, to work it up into something else; to use it - none of these physical circumstances, nor all united, convey the idea of property. A piece of stuff which is actually in the Indies may belong to me, while the dress I wear may not. The aliment which is incorporated into my very body may belong to another, to whom I am bound to account for it. ${ }^{14}$

Here, Bentham expresses the idea that there is a logical equivalence between material things and visible things: there cannot exist a material thing that cannot be seen and there cannot exist a visible thing that is not material. Given this assumption, Bentham wonders whether property is such a thing. To answer this question, he lists a set of material (and therefore, visible) circumstances that are normally associated to the concept of property: to have a thing in my hands, to keep it, to create it, to sell it (i.e., in this case, to give that thing to another person in exchange for money), and to transform it. When we perceive one or more of these circumstances by sight, we are not able to say with absolute certainty whether property exists or, in case it exists and we know it, how it exists. For example, by simply seeing a good in a person's hands, we cannot say whether that or another person has the property of that good. This means that property cannot be seen and, therefore, given our initial assumption, that it cannot be something material: more precisely, the reference of "property" in its second use cannot be something material.

This is what seems to motivate the acceptance of the negative thesis among other philosophers as well. For example, we find the same line of reasoning advanced by Felix S. Cohen in an imaginary dialogue with his students:

$B$. Well, here is a book that is my property. You can see it, feel it, weigh it. What better proof could there be of the existence of private property?

C. I can see the shape and color of the book very well, but I don't see its propertiness. ${ }^{15}$

These lines aim to show that the perceivable attributes of an object of property (e.g. the shape and the colour of a book) cannot make us see property. This is because by simply seeing them, we cannot know that that object is an object of property.

Of course, if one required the reference of a word to be a material object or a material state of affairs, one could say that a sense and a reference for the word "property" do not exist. But, if we maintain that the existence of the reference of the word "property" does not require the material character of such reference, we can proceed to search for it and for the sense of "property".

14 Bentham 1931: 112.

15 F. S. Cohen 1954: 359. 


\subsection{A positive thesis}

Now that we have seen what "property" in its second use does not designate, it is possible to say what it does designate. Consider first, that if the something that the term designates is not a material thing, then it must be something immaterial.

To understand precisely what this something is, we can more closely analyse the second use of "property" in some of the sentences seen above. By using the sentence "This book is the object of my property", for example, I can tell someone else that he or she should not take that book. The sentence "This contract concerns the property of confidential information" signals the reader that the contract says something about the person who is allowed to use certain information. These examples show that when we try to explain the function of such sentences, we must make use of such words as "should" and "allow". This, in turn, leads us to recognize that what "property" designates in such cases (and, therefore, its sense as well) is connected with deontic modalities. This is not an entirely original idea: various legal philosophers seem to have defined property as a set of elements that can be seen as immaterial entities related to the notion of deontic modality.

An example of such a definition is provided by Wesley N. Hohfeld, who claims that, if we suppose that A is the fee-simple owner of a land, his property is a "complex aggregate of rights (or claims), privileges, powers, and immunities". 16 Such legal positions provide a regulation for specific relations, which exist between the owner and the other persons, and which always regard the thing owned. Of course, for every legal position held by the owner, a correlated legal position (i.e. duties, no-rights or no-claims, liabilities, disabilities) is held by another person. So, by relying on Hohfeld's analysis, one could say that property is a set of legal positions, which, given the relations between each of them and their correlative legal positions, regulate the relations between the owner and the other persons as regards a certain good.

A similar kind of analysis is employed by Honoré. ${ }^{17}$ He describes the liberal concept of individual ownership as a set of certain subjective legal positions, which, again, always regard the thing owned. The set includes different rights, but also subjective legal positions that are not rights and that are disadvantageous for the owner: the duty to prevent harm; ${ }^{18}$ liability to execution. The elements listed by Honoré are not individually necessary conditions, but they may be jointly sufficient conditions to use the term "owner". Although Honoré does

16 Hohfeld 1917: 746. See also the treatment of property offered in Hohfeld 1913: 21-24.

17 Honoré 1961.

18 This incident is described in this way in Honore 1987: 174, but, in the original version of the text, it is described as the prohibition of harmful use: see Honoré 1961: 123. 
not deal with the concept of property as I have described it, it seems reasonable to suppose that, given his analysis, this concept could be described as a set of advantageous and disadvantageous subjective legal positions that regulate the relations between persons in connection with goods (if we suppose that, in this case, "property" works as a synonym of "ownership"). In a way, Honoré specifies the positions that characterize a certain conception of property, without claiming that the positions listed are necessary and sufficient conditions to speak of ownership.

An analogous approach to the definitional problem of property is employed by Frank Snare. ${ }^{19}$ Snare claims that there are "rules which are constitutive of the very notion of property". 20 These rules regulate the behaviour of the owner and others with respect to the good and, when one uses a sentence like "A owns P", they are implicitly referred to:

Our claim is that when one says that $\mathrm{A}$ owns $\mathrm{P}$ he is presupposing a set of conventions which are intended to regulate the behavior of $\mathrm{A}$, as well as others, with respect to $\mathrm{P}$. In a similar manner the concept of pawn presupposes a set of conventions which are intended to guide our actions in the chess game..$^{21}$

Two more recent definitions of property follow a similar path. Jeremy Waldron claims that " $[t]$ he concept of property is the concept of a system of rules governing access to and control of material resources",22 and Stephen R. Munzer writes:

The idea of property [...] involves a constellation of Hohfeldian elements, correlatives, and opposites; a specification of standard incidents of ownership and other related but less powerful interests; and a catalog of "things" (tangible and intangible) that are the subjects of these incidents. Hohfeld's conceptions are normative modalities. In the more specific form of Honorés incidents, these are the relations that constitute property. Metaphorically, they are the "sticks" in the bundle called property. 23

The immaterial elements referred to in all these definitions are different, but they are always connected to the notion of deontic modality.

\section{THE CONCEPT OF PROPERTY}

The conclusion just reached can be specified by saying that the immaterial elements, which are members of the different sets identified with property from time to time by the various definitions seen before, have a common component:

19 Snare 1972.

20 Snare 1972: 201.

21 Snare 1972: 201-202. For the list and the content of the rules in question, see Snare 1972: 202204.

22 Waldron 1985: 318. The same definition is used in Waldron 1988: 31.

23 Munzer 1990: 23. 
legal positions, rules, and normative modalities are not the same thing, but each of them is composed of one or more of the basic deontic modalities (i.e. obligatory, permitted, prohibited), in the sense that each of them requires one or more deontic modalities in order to be described. This means that, firstly, all those immaterial elements can be described as deontic modalities, although they are not reducible to deontic modalities. So, both a set of rules and a set of legal positions, for example, can be described as sets of deontic modalities, although they are not reducible to sets of deontic modalities and therefore differ from each other. Secondly, all the immaterial entities that appear in the examined definitions have the same function: they regulate the relations between persons in connection with goods, although the more specific aspects of the regulation in question can change depending on the specific definition one chooses. Therefore, the common idea behind the definitions seen thus far is that property is a set of deontic modalities that regulate the relations between persons in connection with goods. By relying on this conclusion and trying to specify it, we may say that the concept of property is this: a set of one or more deontic modalities that regulate the relations between persons in connection with one or more goods.

The most important reason why it is necessary to specify that the set of deontic modalities identifiable with the concept of property may contain one deontic modality that regulates the relations between persons in connection with one or more goods is that there are accounts of property that identify property with one right, which could be described as (but not reduced to) one deontic modality of that kind. ${ }^{24}$ James E. Penner offers one of the most prominent examples of such an account. ${ }^{25}$ According to Penner, "property is the right to determine how particular things will be used",26 and "exclusion is [...] the formal essence of the right"; 27 in other words, property is the right of exclusive use. Now, the right to freely determine how particular things will be used could be described by saying that it is permitted only to someone to determine how particular things will be used, and this means that this right is describable as (but not reducible to) one deontic modality that regulates the relations between persons in connection with one or more goods. Therefore, the minimal sense of the term "property" can be seen as implied by this way of describing conceptions of property like Penner's.

It is also necessary to comment on two elements that play an important role in my definition of "property": the terms "persons" and "goods". It is obvious

24 This specification, however, is not strictly necessary, since the expression "a set of deontic modalities" may be used to designate a set that includes one deontic modality or more than one deontic modality.

25 See especially Penner 1997.

26 Penner 1997: 5.

27 Penner 1997: 71. 
that the concept of property does not provide a definition of "person" or "good". These two terms can be defined only by referring to specific linguistic communities that establish, on the one hand, which entities can be labelled as "persons" and, on the other hand, which entities can be labelled as "goods". Once these qualifications have been realized, it becomes possible to use one or more deontic modalities to regulate the relations between the entities regarded as persons in connection with one or more of the entities regarded as goods: it is this operation that determines the rise of property. This means that, theoretically, the concept of property can be applied to anything, but its actual application depends on two things: $i$. the decision to qualify some things as persons and some other things as goods; $i$. the decision to use one or more deontic modalities to regulate the relations between persons in connection with one or more goods. Both of these decisions are determined by criteria that are not specified by the concept of property and that are therefore external to this concept.

\section{CONCEPT AND CONCEPTIONS OF PROPERTY}

As mentioned above, the concept of property differs from the conceptions of property. Indeed, it does not provide a closed list of deontic modalities that regulate the relations between persons in connection with one or more goods, and it does not specify how these modalities are used to regulate the relations in question. It simply says that property is a set of one or more deontic modalities that regulate the relations between persons in connection with one or more goods. The members of the set and the ways they are used to regulate the relations between persons in connection with one or more goods change depending on the legal system or theorist. So, this definition of "property" is similar to the definition of "law" provided by normativism, according to which law is a set of norms. This definition does not state the contents of the norms that are members of the set that law is because their contents change depending on the legal system. Although, in any legal system, law is always a set of norms. To find a specific set of one or more deontic modalities that regulate the relations between persons in connection with one or more goods is to find one set of one or more of such deontic modalities, which is not the concept of property. However, any specific set that we can find in this way is always describable at the minimal level as a set of one or more deontic modalities that regulate the relations between persons in connection with one or more goods.

This is the key to understanding a remark made by Wittgenstein that was reported by Norman Malcolm:

When in very good spirits he would jest in a comical manner. This took the form of deliberately absurd or extravagant remarks uttered in a tone, and with a mien, of affected seriousness. On one walk he 'gave' to me each tree that we passed, with the 
reservation that I was not to cut it down or do anything to it, or prevent the previous owners from doing anything to it: with those reservations it was henceforth mine. ${ }^{28}$

This remark helps us understand that one can use the concept of property in relation to a thing (and say, for example, "This thing is mine") even when the deontic modalities included in the set give rise to the prohibition to do anything with that thing and to the prohibition to prevent the previous owners from doing anything with that thing: this is a conception of property, i.e. a way to decline the concept of property. Since the concept of property is a set of one or more deontic modalities that regulate the relations between persons in connection with one or more goods, we can recognize this concept even in the presence of the bizarre declension described by Malcolm.

The elements that compose the concept of property are necessary and sufficient conditions for the use and the recognition of this concept, but they are necessary and not sufficient conditions for the use and the recognition of a conception of property. To determine what "property" means in a specific legal system requires one to know the concept of property because every conception of property is a declension of that concept. But this is only a starting point. It is not sufficient if we want to know how that concept is declined, i.e. which deontic modalities are (or which deontic modality is) employed in a legal system to regulate the relations between persons in connection with one or more goods and how those modalities are (or that modality is) used for this purpose.

\section{THE OTHER USE OF "PROPERTY”}

We can now return to the other use of the term "property" described above, i.e. the use of it as a designator of goods. I think that this use is a figure of speech. This figure of speech is a synecdoche, more precisely the synecdoche that consists in employing a whole to designate a part. It is the figure of speech we employ, for example, when we say "You have wonderful blue eyes". In this case "eye", which is a term for a whole, designates the iris, which is only a part of the eye (i.e. a part of a whole): the eye is not blue, but only the iris is. Now, if the concept of property is a set of one or more deontic modalities that regulate the relations between persons in connection with one or more goods, to use the term "property" as a designator of one or more goods means to use a whole (the concept of property) to represent a part of this whole (the concept of one or more goods). ${ }^{29}$ By saying "This book is my property", I mean that a certain

28 Malcolm 2001: 29. A part of this passage is quoted also by Ackerman (1977: 233).

29 One could reply that goods are (or one good is) the object of the concept of property. My answer is that the fact that "one or more goods" is a necessary component of the definition of the term "property" makes the concept of one or more goods a part of the concept of property. And this does not exclude talk of goods (or of one good) as the object of property. In the same 
book is a good and that the relations between persons in connection with that good are regulated by a set of one or more deontic modalities. The idea that this use of property is parasitic upon the concept of property can already be found in Bentham:

It is to be observed, that in common speech, in the phrase the object of a man's proper$t y$, the words the object of are commonly left out; and by an ellipsis, which, violent as it is, is now become more familiar than the phrase at length, they have made that part of it which consists of the words a man's property, perform the office of the whole. ${ }^{30}$

The explanation of this use of the term "property" can tell us something interesting about the classic contrast between the image of property as a thing and the image of property as a bundle. ${ }^{31}$ The first image arises from the synecdoche described here: the possibility of using "property" to designate goods by that figure of speech makes us naturally think that property is the thing identified as a good. The use of this image can be ultimately explained by appealing to the concept of property. The second image is actually a metaphor, ${ }^{32}$ potentially able to express any single definition of "property" that identifies the sense of this term with a set of immaterial entities. Since any definition of this kind is always a declension of the same concept seen before, this concept can be used to explain the use of this image as well. This is why both images can be seen as harmonically consistent with the concept of property. Why, however, is it so easy to oppose the two? The reason is that the image of property as a thing is often used to express with a greater efficacy the idea that property is one exclusive right over a thing, and not a set of entities (for example, rights or norms) related to a thing. This happens because using the synecdoche mentioned above makes us immediately think of a thing, and it thereby makes it easier for us to think of property as a single right over a thing. However, this idea can be connected to the concept of property in the way I have tried to show by dealing with Penner's account of property.

\section{OWNERSHIP, PROPERTY RIGHTS, AND CONTRACT RIGHTS}

The relation between the concept of property and other concepts that we recognize as belonging to the same area must now be clarified: more specifically, I will concentrate on the concept of ownership and on the concept of a property right.

way, a biography may be defined as a description of a person's life, but we may also say that the object of a biography is a person's life.

30 Bentham 1970: 211, footnote 12.

31 See Nash 2009: 692-707.

32 On this metaphor, see Penner 1996: 713, footnote 8. 
First, the concept of ownership coincides with the concept of property in that the concept of ownership, as well as the concept of property, consists in a set of one or more deontic modalities that regulate the relations between persons in connection with one or more goods. This is why, as already mentioned, we can recognize synonymy between the two terms.

Second, the concept of a property right is included in the concept of property. Indeed, the sense of the expression "property right" consists in a set of one or more deontic modalities that regulate the relations between persons in connection with one or more goods, but these deontic modalities are (or this deontic modality is) advantageous for the holder of the property right. Indeed, when we use the expression "property right", we do not want to signal that the holder of the right has a legal position that is not an advantageous position. Whereas the concept of property is a set that includes one or more advantageous and/or disadvantageous deontic modalities, the concept of a property right is a set that includes only one or more advantageous deontic modalities: the concept of a property right is a subset of the concept of property. ${ }^{33}$

This treatment of the concept of a property right raises an important concern: does it allow one to distinguish between property rights and contract rights? Although it is not possible to examine this problem at length here, it is possible to say that the answer is affirmative. Of course, given the preceding conceptual analysis, a contract right can be described as a set of one or more deontic modalities that regulate the relations between persons, and, therefore, if a contract regards a good, a contract right deriving from that contract can be described as a set of one or more deontic modalities that regulate the relations between persons in connection with that good: in this case, the concept of property and the contract right involved coincide. Moreover, when the deontic modalities (or the deontic modality) identifiable with the contract right are (or is) advantageous to the holder of that contract right, the concept of a property right and the contract right involved coincide. Such coinciding, however, only occurs in the two cases just described. This means that the difference between the concept of a contract right, on the one hand, and the concepts of property and of a property right, on the other, is that the connection with one or more goods is not a necessary component of the former, whereas it is a necessary component of the latter two. In other words, the relation between the concept of property and the concept of a property right is the relation between a set and a subset; instead, the relation between the concept of a contract right and the concept of property, as well as the relation between the concept of a contract right and the concept of a property right, is the relation between two intersecting sets. More precisely, then, the last two relations exist between the concept

33 Munzer (1990: 24) supports this thesis as well, although he formulates it in slightly different terms. 
of property and the concept of a property right, on the one hand, and a specific type of contract right (which is not identifiable with the concept of a contract right), on the other hand. In conclusion, the distinction between contract rights and property rights can still be maintained, in that the concept of a contract right, as stated, does not include the connection with one or more goods as one of its necessary components, whereas this element is a necessary component of both the concept of property and the concept of a property right.

\section{CRITERIA TO APPLY THE CONCEPT OF PROPERTY}

Recall that the concept of property does not contain a definition of the terms "person" or "good". There are external criteria that determine whether and to what extent these two terms can be applied. Once this application has been realized, the choice to use a set of one or more deontic modalities to regulate the relations between the entities qualified as persons in connection with one or more of the entities qualified as goods determines the application of the concept of property. And this choice too depends on elements that are not included in the concept of property.

The way these choices work can be shown by discussing some specific cases. The first is the case of slavery. The possibility of slavery, i.e. of property of human beings, becomes effective only if a community: $i$. decides to qualify certain human beings as goods and other human beings as persons; $i$. decides to employ one or more deontic modalities to regulate the relations between the human beings qualified as persons in connection with one or more of the human beings qualified as goods. Therefore, to exclude that a human being can be qualified as a good does not depend on the concept of property, but on a moral theory: the concept of property does not tell us that human beings can be goods or that they cannot, and it does not tell us whether, once certain human beings have been qualified as goods, one or more deontic modalities can or cannot be employed to regulate the relations between those who are qualified as persons in connection with one or more of them. This view is expressed very clearly by Patrick J. Fitzgerald:

The reason why it seems natural that such things [as human beings] should be incapable of ownership is that we have accepted certain value judgments in regard to them. Having set our hearts against slavery, we will not allow persons to be the subject of ownership at law. ${ }^{34}$

Connected to questions about the possibility of slavery are questions about the possibility of self-ownership. It is impossible to give an extensive treatment of this subject here, but it is possible to wonder whether it is sensible to speak

34 Fitzgerald 1966: 252. 
of self-ownership, given the conceptual analysis provided in the preceding paragraphs. The answer is affirmative. If one keeps in mind that ownership is, at a minimal level, a set of one or more deontic modalities that regulate the relations between persons in connection with one or more goods, then one realizes that for self-ownership to exist, it is first necessary to think about oneself in dualistic terms (otherwise, it would be impossible to distinguish the two things that must be regarded respectively as a person and as a good). Indeed, if I conceive myself as composed of something, which I identify as a person, and of something else, which I identify as a good, then I can also admit that the relation between the two be regulated by a set of one or more deontic modalities: the good in this case could be called "self", and this would make it sensible to speak of "self-ownership".

Another interesting case regards stars. It seems absurd to say that we can own stars, although it is not strange to qualify them as goods. The reason why it seems difficult to apply the concept of property to stars yet is that they are not physically disposable to us. It seems impossible to use one or more deontic modalities to regulate the relations between persons in connection with a good that is not materially available to those persons. This idea can result from Hegel's notion of a thing. According to Joachim Ritter, Hegel claims that a thing is only a natural object "capable of becoming a matter of legal transaction and thus standing at the disposal of human beings"; 35 so, "[e]verything in the realm of nature that does not in principle stand at human disposal, such as the sun and the stars, remains a nonthing in the legal sense". 36 This view is supported by Fitzgerald as well. He implies that it is not logically impossible to apply ownership to stars. It is the absence of control over them that prevents us from doing so. However, he admits that the sun could be recognized as an object of ownership, given its physical position:

Even such objects as the sun, which, we may guess, will never be subject to human control, are not things to which the concept of ownership is completely inappropriate. A system of law under which the king owned the sun and was entitled to charge a fee from those who benefited from its rays would be perfectly possible. ${ }^{37}$

A last interesting case is the case of air. Air is an abundant resource, and this is why Felix S. Cohen remarks that there is no property in air. ${ }^{38}$ Fitzgerald, again, shares the same view, by noticing that it is not a logical impossibility that prevents us from admitting that such resources as air can be owned; simply, "we feel that there is enough of these for all men and that therefore it is only fair

35 Ritter 2004: 108.

36 Ritter 2004: 108. Indeed, Hegel claims that for something to be a thing this something must be differentiated from the free spirit, and this implies the relation described by Ritter: "What is immediately different from the free spirit is, for the latter and in itself, the external in general - a thing [Sache], something unfree, impersonal, and without rights" (Hegel 1991: 73).

37 Fitzgerald 1966: 252.

38 F. S. Cohen 1954: 364. 
that they should be open to all and owned by none". 39 On the contrary, it is the scarcity of the resources we need that leads to the creation of forms of property, as Hart notes. ${ }^{40}$

These examples clearly show that defining the concept of property is not sufficient for establishing exactly how it can be applied. This is not only because it is different from the conceptions of property, but also because it does not establish which features an entity should have in order to be qualified as a person or a good, and under which conditions one or more deontic modalities can be employed to regulate the relations between persons in connection with a certain good.

\section{PROPERTY AND TRANSFER}

To accept the notion of property as it has been described until now may lead to a problem of self-reference. This problem arises if one claims that property is a set of rights (which, in light of the above, could be regarded as a conception of property) and that these rights are therefore the components of property, or, if you prefer, the constitutive rights of property. One could then go on to say that one of these rights should or could be the right to transfer property and that to transfer property would be to transfer all of its components, among which is the right to transfer property. So, if we suppose that the constitutive rights of property are R1, R2, and R3 (R3 being the right to transfer property), then R3 could be described as the right to transfer R1, R2, and R3. Such a right would then be partially self-referring, and this is a problem if we accept the idea that partially self-referring sentences are partially meaningless. ${ }^{41}$

There is, however, a way to solve this problem. It consists in denying the right to transfer property the status of a constitutive right of property. This means that in our example R3 is the right to transfer property and property is R1 and R2 (the constitutive rights of property), but not R3; self-reference is avoided once we admit that the right to transfer property is not a component of property. Just as the physical possibility of giving someone an object is not a component of that object, the deontic possibility of transferring a set of rights is not a component of that set of rights. 42

39 Fitzgerald 1966: 252.

40 Hart 2012: 196.

41 On this idea, see Ross 1969.

42 A similar conclusion is supported by Thon (1878: 327-335). In particular, he claims that the power to transfer property cannot be a part of property because what transfers something cannot be, at the same time, what is transferred. To defend this idea, Thon notes that if I throw a stone, no one would say that the stone gave me the strength to throw it (Thon 1878: 328), which means that my strength is not a part of the stone. 
This solution, of course, seems counterintuitive, since the idea that property includes the deontic possibility of its transfer as one of its necessary components is commonly held. But that it is not so can be shown if one focuses on state-owned goods: when legal norms establish that such goods cannot be transferred, they are described as property, and the expression "state-owned good" itself shows that the concept of ownership (and, therefore, given the treatment of ownership offered above, the concept of property) is applied in this case.

Moreover, other authors seem to accept, at least in certain cases, the thesis of the separability between property and transfer. For example, Penner claims that

it is not unconceivable that one might own untransferable property. [...] [I]f the government suddenly placed a ban on the transfer of houses their owners would not, necessarily, suddenly be without property. [...] [U]ntransferable property is not inconceivable. ${ }^{43}$

Avihay Dorfman provides other interesting considerations. He proposes an account of private ownership that "renders the connection between the right (of alienation) and the idea (of private ownership) a conceptual one",44 but he does not equate the idea of private ownership with the idea of ownership. According to him, "[s] evering this power [to alienate] from owners turns them, in matters of exchange and commerce, into the patients of a central planner, devoid of any control over the transfer and reassignment of their own objects".45 But in such a case, although the transferability of property is removed, we are still dealing with a "picture of ownership - personal ownership": 46 it is "qualitatively different from the idea of private ownership" 47 but it is still ownership. Subsequently, due to the relation of synonymy between "ownership" and "property" seen before, it seems possible to distinguish the idea of private property from the idea of personal property without denying that they are different declensions of one and the same concept of property.

In conclusion, the solution to the problem of self-reference here described can explain why we find it appropriate to use the word "property" even to refer to goods that are not allowed to be transferred. This use emerges as entirely plausible once we admit that transferability is not a constitutive element of the concept of property. The difficulty of such an admission simply results from the

43 Penner 1997: 113. More precisely, Penner states that "the right of exclusive use intrinsically embraces transfer" (Penner 1997: 86), but that "restrictions on use and alienability strike at the right of exclusive use not so much by their extent, but in view of the purpose for which they are instituted, interpreted in light of the prevailing normative context" (Penner 1997: 103). So, the possibility of untransferable property depends on the reason for such restrictions. More specifically, see Penner 1997: 100-103.

44 Dorfman 2010: 34.

45 Dorfman 2010: 4.

46 Dorfman 2010: 4.

47 Dorfman 2010: 4. 
frequency of the transferability of our property; but to be a frequent element of something does not mean to be a necessary element of that something.

\section{IS THE KNOWLEDGE OF THE CONCEPT OF PROPERTY USEFUL?}

Now that the conceptual analysis of property has been completed, it is possible to focus on whether the identification of the concept of property has some utility. By identifying this concept, my aim is not to propose an alternative to the conceptions of property traceable in the legal-philosophical literature, some of which have been described and discussed above. Rather, I want to show that all these conceptions, although different, have something in common, and therefore, that the contrast between them is placed at a level of sense different from the one at which the concept of property can be found.

Moreover, as mentioned, the concept of property is not a peculiarity of legal language, because it is shared by ordinary language as well: this concept can explain the different uses of the term "property" typically found in both languages. Its analysis, then, partially serves to show how the two languages are related: legal language shares part of its semantic content with ordinary language, ${ }^{48}$ and this kind of contact may be located at the level of the minimal senses (i.e. concepts) of certain words that are used in both languages, such as "property".

The possible utility of having identified the concept of property, then, is that this operation allows one to trace the boundaries within which debates about the meaning of "property" take place and will probably continue to take place. The reason for this is that these debates revolve around those elements that once added to the concept of property, give rise to conceptions of property: to propose a conception of property that cannot be placed within the boundaries set by the concept of property is possible, but difficult, since it means advancing a definition of "property" that departs too far from ordinary language.

Apparently, the view that conflicts most strongly with these ideas is that the relation between the references of the term "property" is given by family resemblances. Appealing to the notion of family resemblance is not, however, necessarily incompatible with the proposal of a unitary definition of "property". Consider, for example, the account of property offered by Hanoch Dagan, who explicitly uses the notion of family resemblance:

Property [...] is an umbrella of institutions bearing a family resemblance. All these institutions mediate the relationship between owners and nonowners regarding a re-

48 On the relationship between legal language and ordinary language, see Jori 2016. 
source, and in all property institutions owners have some rights to exclude others and to exclusively determine the resource's agenda. ${ }^{49}$

In other words,

[p]roperty is an umbrella for a set of institutions - property institutions - bearing family resemblances. Each such property institution entails a specific composition of entitlements that constitute the contents of an owner's rights vis-à-vis others, or a certain type of others, with respect to a given resource. 50

In this explanation, property can always be described, at a minimal level, as a set of institutions that mediate the relationship between owners and nonowners regarding a resource, and this can be seen as a unitary, though very general, definition. So, if the appeal to family resemblances does not exclude the existence of such a definition, the idea that a unitary concept of property exists may still be defended.

\section{References}

Ackerman, B. A. (1977). Private property and the Constitution. New Haven, CT: Yale University Press.

Bentham, J. (1931). The theory of legislation ( $\mathrm{R}$. Hildreth, Trans.). London, England: Kegan Paul, Trench, Trubner \& Co. (Original work published 1802).

Bentham, J. (1970). An introduction to the principles of morals and legislation. London, England: The Athlone Press. (Original work published 1789).

Brożek, B. (2015). On tû-tû. Revus: Journal for Constitutional Theory and Philosophy of Law, 27, 15-23.

Claeys, E. R. (2018). Use and the function of property. The American Journal of Jurisprudence, 63(2), 221-258.

Cohen, F. S. (1954). Dialogue on private property. Rutgers Law Review, 9(2), 357-387.

Cohen, M. R. (1927). Property and sovereignty. Cornell Law Quarterly, 13(1), 8-30.

Dagan, H. (2011). Property: Values and institutions. Oxford, England: Oxford University Press.

Dorfman, A. (2010). Private ownership. Legal Theory, 16(1), 1-35.

Fitzgerald, P. J. (Ed.). (1966). Salmond on jurisprudence (12 $2^{\text {th }}$ edition). London, England: Sweet \& Maxwell. (Original work published 1902).

Frege, G. (1952). On sense and reference (M. Black, Trans.). In P. Geach \& M. Black (Eds.),
Translations from the philosophical writings of Gottlob Frege (pp. 56-78). Oxford, England: Basil Blackwell. (Original work published 1892).

Harris, J. W. (1996). Property and justice. Oxford, England: Clarendon Press.

Hart, H. L. A. (1954). Definition and theory in jurisprudence. Law Quarterly Review, 70(1), 37-60. (Original work published 1953).

Hart, H. L. A. (1968). Punishment and responsibility: Essays in the philosophy of law. Oxford, England: Clarendon Press.

Hart, H. L. A. (2012). The concept of law (3rd edition). Oxford, England: Clarendon Press. (Original work published 1961).

Hegel, G. W. F. (1991). Elements of the philosophy of right (H. B. Nisbet, Trans.). Cambridge, England: Cambridge University Press. (Original work published 1820).

Hohfeld, W. N. (1913). Some fundamental legal conceptions as applied in judicial reasoning. Yale Law Journal, 23(1), 16-59.

Hohfeld, W. N. (1917). Fundamental legal conceptions as applied in judicial reasoning. Yale Law Journal, 26(8), 710-770.

Honoré, A. M. (1961). Ownership. In A. G. Guest (Ed.), Oxford essays in jurisprudence: A collaborative work (pp. 107-147). London, England: Oxford University Press.

Honoré, T. (1987). Ownership. In T. Honoré, Making

49 Dagan 2011: xvii.

50 Dagan 2011: 42. 
law bind: Essays legal and philosophical (pp. 161-192). Oxford, England: Clarendon Press. (Original work published 1961).

Jori, M. (2016). Legal pragmatics. In A. Capone \& F. Poggi (Eds.), Pragmatics and law: Philosophical perspectives (pp. 33-60). Cham, Switzerland: Springer.

Malcolm, N. (2001). Ludwig Wittgenstein: A memoir (2nd edition). Oxford, England: Clarendon Press. (Original work published 1958).

Munzer, S. R. (1990). A theory of property. Cambridge, England: Cambridge University Press.

Munzer, S. R. (2013). Property and disagreement. In J. Penner \& H. E. Smith (Eds.), Philosophical foundations of property law (pp. 289-319). Oxford, England: Oxford University Press.

Nash, J. R. (2009). Packaging property: The effect of paradigmatic framing of property rights. Tulane Law Review, 83(3), 691-734.

Penner, J. E. (1996). The "bundle of rights" picture of property. UCLA Law Review, 43(3), 711-820.

Penner, J. E. (1997). The idea of property in law. Oxford, England: Oxford University Press.

Rawls, J. (1971). A theory of justice. Cambridge, MA: Harvard University Press.

Ritter, J. (2004). Person and property in Hegel's
Philosophy of right (\$\$34-81) (N. Walker, Trans.). In R. B. Pippin \& O. Höffe (Eds.), Hegel on ethics and politics (pp. 101-123). Cambridge, England: Cambridge University Press. (Original work published 1961).

Ross, A. (1957). Tû-tû. Harvard Law Review, 70(5), 812-825. (Original work published 1951).

Ross, A. (1958). On law and justice (M. Dutton, Trans.). London, England: Stevens \& Sons Limited. (Original work published 1953).

Ross, A. (1969). On self-reference and a puzzle in constitutional law. Mind, 78(309), 1-24.

Sartor, G. (2009). Understanding and applying legal concepts: An inquiry on inferential meaning. In J. C. Hage \& D. von der Pfordten (Eds.), Concepts in law (pp. 35-54). Dordrecht, Netherlands: Springer.

Snare, F. (1972). The concept of property. American Philosophical Quarterly, 9(2), 200-206.

Thon, A. (1878). Rechtsnorm und subjectives Recht: Untersuchungen zur allgemeinen Rechtslere. Weimar, Germany: Hermann Böhlau.

Waldron, J. (1985). What is private property? Oxford Journal of Legal Studies, 5(3), 313-349.

Waldron, J. (1988). The right to private property. Oxford, England: Clarendon Press. 